\title{
DESDOBRO DE ESTIPE DE PUPUNHA (BACTRIS GASIPAES KUNTH) PARA NOVOS PRODUTOS
}

\section{SAWING OF "ESTIPE" OF PUPUNHA (BACTRIS GASIPAES KUNTH) FOR NEW PRODUCTS}

\author{
Agatha Araújo Trindade, M.Sc. (UFAM); \\ Fábio H. Dias Máximo, M.Sc. (UFAM) \\ Palavras Chave \\ Estipe de Pupunha; Configuração de Produtos; Rendimento e Eficiência
}

\section{Key Words}

Stem of Pupunha; Configuration of Products; Yield and Efficiency

\section{RESUMO}

Estipes de pupunha descartados dos processos produtivos agrícolas são passíveis ambientais. Analisando 15 indivíduos com aproximadamente 10 anos, comprovamos a viabilidade do uso da parte periférica para desenvolvimento de produtos. Para o estudo, dividiu-se o estipe em três secções de $50 \mathrm{~cm}$; posteriormente, dois cortes longitudinais para extração da medula; seguida por secagem controlada em estufa a $103^{\circ} \mathrm{C}$ e; refilamento. Relacionando o volume bruto e o desdobrado das amostras, surpreendentemente o rendimento total foi 94,07\% e eficiência de 20,14 m3/operário/turno. Os resultados comprovaram que os passíveis ambientais podem ser aproveitados na configuração de novos produtos.

\section{ABSTRACT}

Stems of pupunha palm discarded from agricultural processes are considered environmental liabilities. Analyzing 15 individuals with about 10 years, we verified the feasibility of using the peripheral part for product development. For the study, the stipe was divided into three sections of $50 \mathrm{~cm}$; later, two longitudinal cuts for extraction of the marrow; followed by controlled oven drying around $103^{\circ} \mathrm{C}$ and; cut into strips. Relating the gross and unfolded volumes of the samples, surprisingly the total yield was $94.07 \%$ and efficiency of $20.14 \mathrm{~m} 3 /$ worker/shift. The results showed that the environmental liabilities can be used in the configuration of new products. 


\section{INTRODUÇÃO}

Analisando a exploração agroindustrial e as atividades vinculadas na produção e industrialização do palmito no Amazonas, pesquisadores observam que consequentemente à geração de resíduos, causando problemas para o meio ambiente e para os responsáveis envolvidos. Dessa atividade descartam-se a estipe, folhas e bainhas externas, que representam aproximadamente $13 \mathrm{~kg}$ de resíduos (FERMINO et al ,2010) de um único individuo, onde somente a bainha interna presente nesta estipe é comercializada.

Considerando que uma fábrica produz em torno de $131 \mathrm{t}$ resíduo/mês, onde parte desse material, que permanece no local da colheita e no processamento, não apresenta finalidade prática, tornando-se passivo ambiental (SILVA et al. 2009). O mesmo acontece com os indivíduos oriundos do banco de sementes da agroindústria de palmito que produzem sementes de qualidade nos períodos 3 a 10 anos de idade. Esse processo gera como subproduto um volume elevado de estipes, que são abandonados no local (FONSECA, 2010).

No entanto, para tornar a viabilidade da matéria-prima mais abrangente necessita-se da análise quanto ao rendimento e eficiência dando uma visão sistêmica do desempenho, no entorno do aproveitamento do material lenhoso do estipe, que poderá definir a capacidade de produção no uso do material e o desenvolvimento de novos produtos, elementos chave no alcance e manutenção da produtividade, qualidade e competitividade.

Contudo, para o planejamento da capacidade e a determinação da viabilidade. $\mathrm{O}$ trabalho teve como objetivo de analisar a viabilidade do aproveitamento do estipe da pupunha (Bactris gasipaes Kunth) para produção de matéria-prima utilizada em moveis e artefatos. Com grande potencial econômico (GIORDANO, 2007), a pupunha (Bactris gasipaes Kunth.).Já possui aplicação, como exemplo de utilização de seus estipes nas tecnologias de produção de compensados da empresa Fibra Design Sustentável (2011) que descreve o material como lenhoso de alta densidade e rigidez, alcançando um acabamento final de altíssima qualidade devido à superfície lisa, proporcionada pela textura fina. Ações como estas representam uma alternativa ao desmatamento das florestas nativas para obtenção de madeira, criando um processo produtivo em torno da pupunha e agregando valor a um resíduo da agroindústria, permitindo a ampliação do ciclo de vida da espécie.

\section{PROBLEMATIZAÇÃO}

Para suprir a demanda crescente do mercado, novos produtos são confeccionados aumentando o consumo de recursos naturais e de resíduos sólidos nos setores urbanos, indústrias e agroindustriais gerando um impacto sobre o meio ambiente (PUPO 2012). Haja visto que uma agroindústria de palmito demanda que uma parte do terreno seja destinada à produção de mudas, que são produzidas a partir das sementes, que são conservadas pelos frutos. Estas são produzidas por palmáceas adultas, com até 10 anos, que é a idade limite para se colher bons frutos e em boa quantidade, o que resulta em muitas mudas sadias (BACELLAR, 2010). Este limite de idade para produção de sementes gera um resíduo, que pode ser aproveitado como matéria-prima para a indústria moveleira e de construção civil, entre outras. A madeira é, então, proveniente dessas geradoras de sementes e oriunda de plantas acima de três anos (LEEUWEN, 2006).

Entretanto, para que haja uma intervenção no uso desses materiais em projetos ecologicamente responsáveis, socialmente relevantes, tecnologicamente apropriados e que atendam aos desejos dos consumidores (GOUVINHAS e FILHO, 2010) necessitam de um planejamento da capacidade de informações quantitativas em relação ao processamento do material descartado. Logo, para o planejamento da capacidade e a determinação da viabilidade é necessário determinar medidas de desempenho entre elas o rendimento e a eficiência na transformação da matéria-prima, bem como atualizar e gerar nas novas informações sobre estipes de pupunha. Assim, surge o problema da pesquisa: rendimento e a eficiência no processamento do estipe de pupunha indicam que o aproveitamento para confecção de novos produtos é viável?

\section{MATERIAIS E MÉTODOS}

\subsection{Local do estudo e Coleta do Material botânico}

O estudo foi realizado em área privada localizado na Rodovia Manoel Urbano (AM 70), Km 08 Parque Real II, zona metropolitana município de Iranduba - Amazonas. Inicialmente houve medição dos DAP's (diâmetro na altura do peito) dos indivíduos selecionados e em seguida realizou-se a derrubada direcionada devido à proximidade dos indivíduos situados em locais propícios a danos, com auxílio de uma motosserra (Husqvarna modelo 288 $\mathrm{xp})$, tendo com o ponto de corte um metro acima do solo.

Foram escolhidos 15 indivíduos com idades médias de 10 a 15 anos. O estipe dos indivíduos foi dividido em: base ou basal, meio e topo ou ápice para melhor orientar a obtenção das amostras, comprimento aproximadamente $50 \mathrm{~cm}$, visando facilitar o processo de 
beneficiamento da parte periférica e posteriormente armazenadas em estufa $103 \pm 20 \mathrm{C}$, havendo a pesagem (em balança de precisão) das amostras até observação de massa constante (Figura 1).

Figura 01: Método de secagem. A. Verificação da massa constante. B. Amostras na Estufa

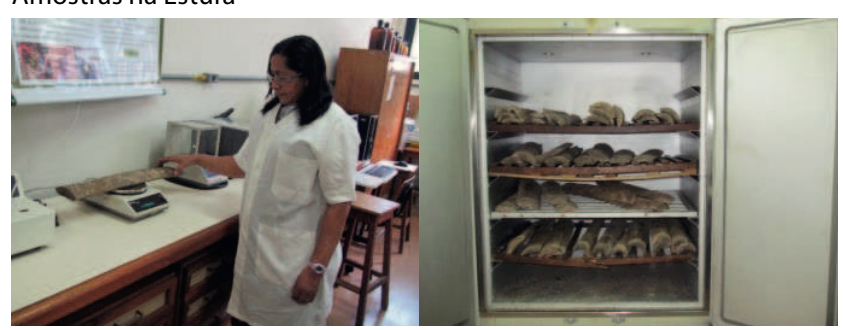

Fonte: Elaborado pelos autores

\subsection{Pré-beneficiamento e desdobro das} amostras

Em cada amostra, foram efetuados dois cortes longitudinais com o auxílio do motosserra, com o intuito de gerar faixas de estipe para facilitar a retirada do tecido medular (esponjoso) encontrado na região central do estipe com auxílio de um facão e organizadas por segmento de identificação da secção correspondente ao estipe (fibra lenhosa). Para o desdobro foram utilizados três maquinários e dividido em duas etapas:

- Na primeira etapa as amostras da secção do meio foram admitidas no processo de desdobro passando pela serra de fita, e as amostras da base e extras na serra circular, onde se realizaram os cortes de modo a diminuir acentuação do arco para obtenção de filetes retos (angulação aproximada) (Figura 2);

- A segunda etapa constituiu na retida da casca e o restante da parte medular ainda presente, passando novamente pela serra circular e na plaina. As amostras da base e extras, por causa da espessura do material lenhoso e sua rigidez. Devido à pouca espessura dos refilos da secção do meio, a retirada da parte medular foi executada na lixadeira utilizando uma lixa de ferro com grão 80.

Figura 02: Visualização do desdobro. A. Serra de Fita. B. Serra Circular

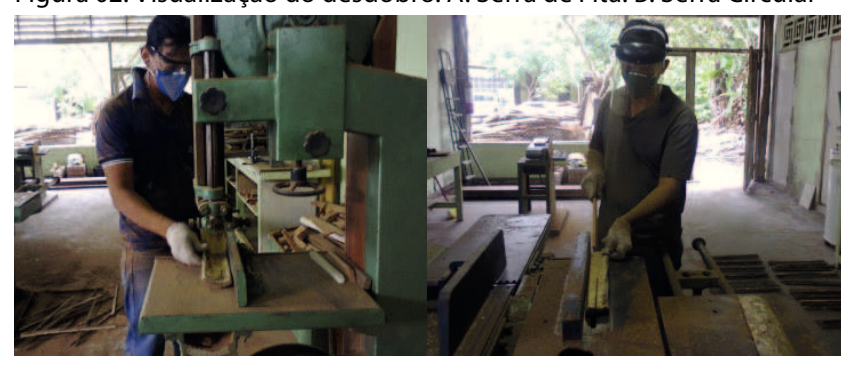

Fonte: Elaborado pelos autores

\subsection{Estimativas volumétricas}

O volume bruto por individuo foi determinado pelo cálculo do cilindro oco, que prevê estimar o volume somente parte periférica e da casca determinado pela equação 1, de modo a obter o volume da amostra sem a parte medular.

Onde:

$$
V_{a}=\pi \times H \times E(1)
$$

$\mathrm{V}_{\mathrm{a}}$ : volume da amostra $\mathrm{m}^{3}$;

$\pi: \mathrm{Pi}$, valor aproximado a 3,14;

$\mathrm{H}$ : comprimento médio das partes das amostras em $\mathrm{cm}$;

E: espessura média das partes das amostras em $\mathrm{cm}$.

Volume Bruto total das amostras foi apurado pela somatória do volume individual de cada indivíduo (Equação 2), obtendo o volume de entrada no desdobro.

Onde:

$$
\mathrm{V}_{\mathrm{t}}=\Sigma \mathrm{V}_{\mathrm{a} 1}+\mathrm{V}_{\mathrm{a} 2}+\ldots+\mathrm{V}_{\mathrm{an}}(2)
$$

$\mathrm{V}_{\mathrm{t}}$ : volume total das amostras selecionadas para o desdobro $\mathrm{m}^{3}$;

$\mathrm{V}_{\mathrm{an}}$ : volume da amostra $\mathrm{n} \mathrm{em} \mathrm{m}^{3}$.

Após o desdobro das amostras, os refilos resultantes foram separados e realizou a medição com o auxílio de trena e paquímetro. Posteriormente houve a cubagem de cada peça do material processado, determinando o volume do desdobro total com a seguinte equação.

$$
\begin{gathered}
V_{\mathrm{s}}=\mathrm{V}_{\mathrm{a} 1}\left(\mathrm{~L}_{\mathrm{a} 1} \times \mathrm{C}_{\mathrm{a} 1} \times \mathrm{E}_{\mathrm{a} 1}\right)+\mathrm{V}_{\mathrm{a} 1}\left(\mathrm{~L}_{\mathrm{a} 2} \times \mathrm{C}_{\mathrm{a} 2} \times \mathrm{E}_{\mathrm{a} 2}\right)+\ldots \\
+\mathrm{V}_{\mathrm{an}}\left(\mathrm{Lan}_{\mathrm{an}} \times \mathrm{C}_{\mathrm{an}} \times \mathrm{E}_{\mathrm{an}}\right)(3)
\end{gathered}
$$

Onde:

$\mathrm{V}_{\mathrm{s}}$ : volume total do desdobro $\mathrm{m}^{3}$;

$\mathrm{V}_{\mathrm{an}}$ : volume da amostra após o desdobro em $\mathrm{n}$;

L: largura média das partes da amostra;

C: comprimento médio das partes da amostra;

E: espessura média das partes da amostra em $\mathrm{cm}$.

O volume de resíduos foi determinado com base na diferença entre o volume das amostras e o volume de serrados obtidos no processamento mecânico, utilizando a equação 4:

Onde:

$$
V_{R}=V_{B}-V_{D}(4)
$$

$\mathrm{V}_{\mathrm{R}}$ : Volume dos resíduos em $\mathrm{m}^{3}$;

$\mathrm{V}_{\mathrm{B}}$ : Volume total do bruto em $\mathrm{m}^{3}$;

$V_{\mathrm{D}}$ : Volume total do desdobro em $\mathrm{m}^{3}$. 
O rendimento volumétrico do material desdobrado, ou seja, percentual entre o volume de material serrado e volume bruto, foi obtido por meio da equação 5 a seguir:

Onde:

$$
\mathrm{R}=\mathrm{V}_{\mathrm{D}} / \mathrm{V}_{\mathrm{B}} \times 100(5)
$$

R: Rendimento em porcentagem;

$V_{D}$ : Volume desdobrado em $\mathrm{m}^{3}$;

$\mathrm{V}_{\mathrm{B}}$ : Volume bruto em $\mathrm{m}^{3}$.

\section{ANÁLISE E DISCUSSÕES SOBRE O RENDIMENTO E EFICIÊNCIA DO DESDOBRO DAS ESTIPES DE PUPUNHA}

\subsection{Observações quanto a estipe de pupunha}

No que diz respeito à parte periférica, há diminuição ao logo do estipe, conforme foram retiradas as amostras. As secções do meio e as da base apresentaram espessura de $0,52 \mathrm{~cm}$ a $0,77 \mathrm{~cm}$ e $0,67 \mathrm{~cm}$ a $3,28 \mathrm{~cm}$. Tal critério pode modificar-se devido à variabilidade genética, idade do indivíduo, bem como ao tipo de solo e questões climáticas.

Considerando a parte periférica do estipe aproveitável. As amostras das seç̧ões do meio e base oferecem potencial de uso, por apresentarem espessuras médias 0,5 cm e 2,2 cm, considerável a modo de obtenção no pré-beneficiamento e desdobro (Figura 3).

Figura 03: Método de secagem. A. Verificação da massa constante. B. Amostras na Estufa

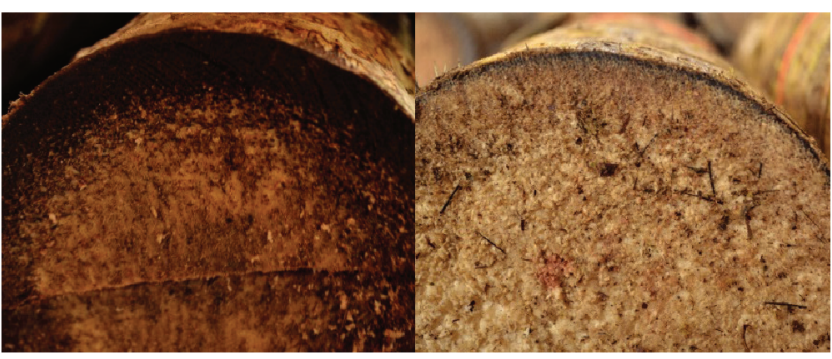

Fonte: Elaborado pelos autores

É indicado a utilização da parte periférica como material lenhoso de alta densidade e rigidez, e aproveitável para confecção de produtos (ROCHA et al , 2002; MADY, 2003; FONSECA, 2010; SILVA, 2010; BACELLAR, 2011), porém a porção de madeira com espessura média de 2cm (MADY, 2003) seria mais apropriada para utilização. Assim, as amostras do ápice ou topo da pupunheira não foram utilizadas no desdobro por não apresentarem visualmente a parte periférica e foram descartadas após a secagem. Fonseca (2010) alega que grande parte do peso apresentado pelas secções foi em razão alto teor de água presente no tecido esponjoso do centro do estipe e a retirada do material susceptivel a fungos e outros agentes degradadores conferirão menor risco de degradação natural da matéria-prima.

Bacellar (2011) analisou a fração volumétrica de fibras de uma amostra retirada a 1,5m de altura e de uma retirada da base, constatando por meio de analise axial, que o corpo de prova basal possui mais fibras orientadas na direção axial. Resultado confirmado por utilizadores da madeira de pupunha que haviam comprovado de forma empírica a maior resistência da madeira basal. Porém a parte periférica encontrada nas amostras da secção do meio do estipe, teve o comportamento similar a amostra da base na realização do desdobro, e apesar estarem na porção menor a $2 \mathrm{~cm}$, ainda correspondem a um material rígido com espessuras média de $0,5 \mathrm{~cm}$.

Tabela 01: Volume bruto e do desdobro das amostras por secção. Legenda: (M) Meio, (B) Base e (EXB) Amostras extras da base.

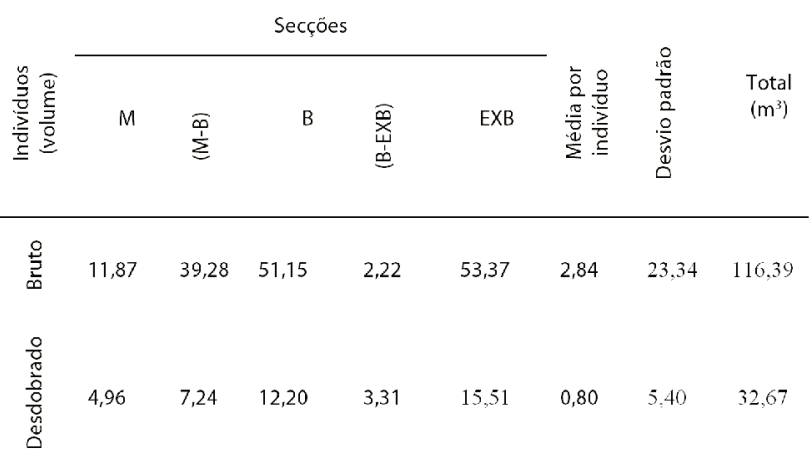

Fonte: Elaborado pelos autores

Abordando as diferenças nos volumétricas das secções, nota-se a diferença de $39,28 \mathrm{~m} 3$ (Tabela 1) entre as amostras do meio e da base no volume bruto, sendo quase equivalentes três vezes o total das amostras da secção do meio, isso se deve a diferença na espessura da parte lenhosa, com média 1,7 cm (Tabela 2). Entre as amostras da base e as extras a diferença dos volumes foi de $2,22 \mathrm{~m} 3$ (Tabela 1), que equivalem a $4,33 \%$ do volume total dos indivíduos da base, com diferença media entre as duas secções de 0,5 cm da espessura (Tabela 2).

Nas diferenças entre os volumes do desdobro, as secções do meio e da base foi 7,24 m3, que correspondem a $22,15 \%$ do volume total do desdobro. Houve também uma diminuição significativa do volume bruto para o volume desdobrado da secção do meio em 41,78\%, esse fator deve-se pela retirada da parte medular, apresentando uma diferença média na espessura de 0,2 cm entre as duas secções (Tabela 2).

Já a diferença entre as amostras da base e as extras é de 3,31 m3 (Tabela 1) e representam 1,01\% do volume 
total do desdobro, havendo aumento no volume entre as secções de $83,72 \mathrm{~m} 3$ que correspondem à diminuição entre espessuras de $0,5 \mathrm{~cm}$ para $0,3 \mathrm{~cm}$ (Tabela 2). As amostras não apresentaram diferença significativa entre as larguras por apresentarem diâmetro médio de $15 \mathrm{~cm}$ (Tabela 2).

Tabela 02: Volume bruto e volume desdobrado das amostras por secção em cm.Legenda: (M) Meio, (B) Base e (EXB) Amostras extras da base.

\begin{tabular}{lccccc} 
& \multicolumn{4}{c}{ M } & \multicolumn{1}{c}{ EXB } \\
\cline { 2 - 6 } & MÉDIA & $(\mathrm{M}-\mathrm{B})$ & MÉDIA & (B-EX) & MÉDIA \\
\hline Material bruto & & & & & \\
Comprimento & 48,9 & 0,7 & 49,6 & 7,2 & 56,8 \\
Espessura & 0,5 & 1,7 & 2,2 & 0,5 & 2,7 \\
Diâmetro & 15 & 0 & 15 & 0 & 15 \\
Material Desdobrado & & & & & \\
Comprimento & 48,1 & 1,5 & 49,6 & 4,51 & 54,11 \\
Espessura & 0,4 & 0,2 & 0,6 & 0,3 & 0,9 \\
Largura & 2,4 & 0,2 & 2,6 & 0 & 2,6 \\
& & & Fonte: Elaborado pelos autores
\end{tabular}

A diferenciação entre secções nos volumes brutos e desdobrados representa variação do fluxo de resíduo gerado e evidenciou a dinâmica que o ocorre quanto à interferência da parte medular e valor da espessura no aproveitamento da matéria-prima. Neste caso, o volume desdobrado sofre influência da espessura da parte periférica e a quantidade do material medular presente na matéria-prima a ser desdobrada.

Ao analisarmos o volume total do descarte no desdobro $(83,71 \mathrm{~m} 3)$, observa-se que a secção do meio apresenta um volume de 6,91 com percentual de $8,26 \%$ do volume total descartado (Tabela 3), mesmo com o descarte de amostras dos indivíduos 2, 7 e 9, e mais a parte medular na secção do meio. As amostras da base e as extras representam 46,52\% e 45,22\%(Tabela 3), esse percentual alto está relacionado aproximação das medidas entre os refilos obtidos no desdobro, havendo um maior descarte de material, e a quantidade do tecido medular presente no volume residual.

Tabela 03: Volume residual por secção.

\begin{tabular}{ccc} 
& \multicolumn{2}{c}{ Volume residual } \\
AMOSTRAS & $(\mathrm{m} 3)$ & $(\%)$ \\
\hline Meio & 6,91 & 8,26 \\
Base & 38,94 & 46,52 \\
Extra da base & 37,85 & 45,22 \\
\hline TOTAL & 83,71 & 100
\end{tabular}

Fonte: Elaborado pelos autores

\section{RENDIMENTO}

O maior rendimento percentual com 41,78\% (Tabela 4) foi da secção central. O mesmo ocorre com a secção da base e amostras extras, onde o valor do rendimento é inverso ao do resíduo gerado. As amostras da base e as extras apresentaram percentuais de $23,86 \%$ e $29,07 \%$ (Tabela 4), e ao final as amostras obtiveram um total de $94,71 \%$.

Comparando ao estudo Hillig et al (2006) sobre o rendimento médio de dez serrarias no Estado do Pará, observa-se grande variação de valor, sendo o mais alto igual a $55 \%$ e o mais baixo igual a $27 \%$. Os valores secção da base e amostras extras ( $23.86 \%$ e $29.07 \%$ ) contemplariam a média das serrarias de baixo rendimento e a secção do meio $(41,78 \%)$ um valor intermédio entre os rendimentos das serrarias.

Tabela 04: Valores do rendimento disposto por secção do estipe

\begin{tabular}{|c|c|c|c|}
\hline & VOLUME & INDIVÍDUOS & TOTAL $\left(M^{3}\right)$ \\
\hline \multirow{3}{*}{$\frac{\mathrm{O}}{\mathrm{W}}$} & Bruto & \multirow[b]{2}{*}{15} & 11,87 \\
\hline & Desdobrado & & 4,96 \\
\hline & & Rendimento (\%) & 41,78 \\
\hline \multirow{3}{*}{$\begin{array}{l}\text { 岕 } \\
\text { 品 }\end{array}$} & Bruto & \multirow{2}{*}{15} & 51,15 \\
\hline & Desdobrado & & 12,2 \\
\hline & & Rendimento (\%) & 23,86 \\
\hline \multirow{3}{*}{ 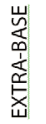 } & Bruto & \multirow{2}{*}{11} & 53,37 \\
\hline & Desdobrado & & 15,51 \\
\hline & & Rendimento (\%) & 29,07 \\
\hline & \multicolumn{2}{|c|}{ RENDIMENTO TOTAL (\%) } & 94,71 \\
\hline
\end{tabular}

Fonte: Elaborado pelos autores

Se consideramos que a classe diamétrica 1 (Tabela 5) expressa o menor diâmetro sendo $31 \mathrm{~cm}$, os rendimentos das secções correspondem a metade do diâmetro da classe. Ao compararmos os dados de Biase (2007) o valor do rendimento da secção as amostras extras da base (29,07\%) ao dobrarmos obteria um valor muito próximo ao da Cambará (59,18\%), que de acordo com autor foi à única espécie a alterar rendimento conforme o aumento do diâmetro das toras (BIASE, 2007).

Tabela 05: Valores fornecidos por Biase (2007) com três espécies tropicais CLASSE ESPÉCIES RENDIMENTO (\%)

\begin{tabular}{ccc}
\hline 1 & Cedrinho & 53,3 \\
$31-40(\mathrm{~cm})$ & Cambará & 59,18 \\
& Itaúba & 49,73 \\
\hline & Média & 54,07
\end{tabular}

Fonte: Elaborado pelos autores

Analisando de modo geral, a amostra do experimento obtiveram uma média por secção de $31,57 \%$, superiores ao rendimento individual da secção da base e as amostras 
extras. Correlacionando os valores do rendimento total e volume residual $(71,41 \%)$, suponha-se que o alto rendimento está associado diferencia volumétrica da relação entre os volumes brutos e desdobrados (Tabela 2).

Projetando o uso do estipe até $25 \mathrm{~cm}$ acima do ponto médio, ponto culminante a visualização da parte periférica, as 15 pupunheiras proporcionariam: um volume bruto total de $166,49 \mathrm{~m} 3$; volume total desdobrado $82,24 \mathrm{~m} 3 ; 84,25$ de volume residual e; $49 \%$ de rendimento médio por indivíduo. Considerando que o rendimento no desdobro varia de $55 \%$ a $65 \%$ para coníferas e entre $45 \%$ e $55 \%$ para folhosas segundo Rocha (2002), considerando que não somente a espécie afeta o rendimento, mas que este será maior ou menor em função da qualidade dos povoamentos, dos equipamentos, técnicas de desdobro e da qualificação profissional dos operários, verifica-se que a pupunheira se enquadra no índice variável para árvores folhosas, presente na literatura. No entanto, ressalta-se que nesta análise, somente as mediações próximas ao ponto médio do comprimento do indivíduo, e uma espessura visível e aproveitável da parte periférica ao logo do estipe foram consideradas.

Segundo Barbosa (1990) o desdobro primário em Roraima apresentou índices de aproveitamento variando de 38,1 a $68,9 \%$, com uma média estadual de $54,2 \%$. Estando abaixo da média estudada por Biase (2007) que foi de $57,96 \%$ em trabalho sobre rendimento e eficiência de três espécies tropicais.

\section{EFICIÊNCIA}

Na TABELA 6 são apresentados os resultados da eficiência técnica por secção do estipe. A eficiência técnica nos dois turnos de trabalho foi de 3,43 e 16,71 m3/operário/turno, com média geral correspondente a 10,07 m3/ operário/turno.

Tabela 06: Resultados da eficiência técnica no desdobro das amostras. Legenda: M. meio. B. base. EB. Amostras extras da base.

\begin{tabular}{|c|c|c|c|c|}
\hline \multirow{2}{*}{ Secção } & \multicolumn{2}{|c|}{ Desdobro } & \multirow{2}{*}{ Operários } & \multirow{2}{*}{$\begin{array}{c}\text { Eficiência } \\
\mathrm{m}^{3} \text { /operário } \\
\text { /turno }\end{array}$} \\
\hline & $\begin{array}{l}\text { Volume } \\
\left(\mathrm{m}^{3}\right)\end{array}$ & Tempo (h) & & \\
\hline$M$ & 4,96 & 11,57 & & 3,43 \\
\hline $\begin{array}{l}B \\
E B\end{array}$ & $\begin{array}{r}12,2 \\
15,51\end{array}$ & 13,27 & 2 & 16,71 \\
\hline & & & Média & 10,07 \\
\hline
\end{tabular}

Para Manhiça (2010) em seu trabalho com quatro classe diamétricas de Pinus sp obteve um valor de 10,18 m3/ operário/turno para desdobro aleatório numa serraria de pequeno porte, sendo que as primeiras classes (1 e 20) juntas perfazem um intervalo diamétrico de $24,0 \mathrm{~cm}$ a $28,0 \mathrm{~cm}$, e classe $3 \mathrm{com} 28,1 \mathrm{~cm}$ a $30,0 \mathrm{~cm}$. Enquanto no desdobro programado a eficiência cai para $8,07 \mathrm{~m} 3$ / operário/turno.

Batista e Carvalho (2007) tendo trabalhado com Eucalyptus spp na avaliação do desempenho da serraria de pequeno porte no desdobro de toras determinaram o valor da eficiência técnica da serraria e encontraram um valor correspondente a 4,96 m3/operário/turno, onde o gênero Eucalyptus sp apresentam maior massa específica em relação as do gênero Pinus sp., sendo muitas vezes, as mais difíceis de serrar.

Em termos de comparação a eficiência da secção do meio apresenta um valor próximo ao obtido por Batista e Carvalho (2007) que corresponde ao gênero Eucalyptus spp, e as amostras da base e extras oferecem um valor superior ao de uma serraria de pequeno porte no desdobro aleatório de Pinus sp (MANHIÇA, 2010).

Nos índices da eficiência do desdobro das amostras, o tempo médio obtido para cada secção varia entre 2 a 8 minutos (Tabela 7). O quantitativo de amostras processadas teve a média de 92, 6 (Tabela 8). Em análise obteve o tempo médio de desdobro para cada secção.

Tabela 07: Tempo médio no desdobro de uma sub-amostras do estipe de pupunha.

\begin{tabular}{cccc} 
& \multicolumn{3}{c}{ MAQUINÁRIO } \\
\cline { 2 - 4 } Secções & \multicolumn{2}{c}{ Serra } & Lixadeira \\
\cline { 2 - 4 } & Fita & Circular \\
\hline$M$ & $4 \mathrm{~min}$ & - & $3 \mathrm{~min}$ \\
B & $8 \mathrm{~min}$ & $2 \mathrm{~min}$ & $4 \mathrm{~min}$ \\
EB & - & $3 \mathrm{~min}$ & -
\end{tabular}

Fonte: Elaborado pelos autores

Tabela 08: Número de amostras desdobradas por dia.

\begin{tabular}{|c|c|c|c|c|c|c|}
\hline & \multicolumn{5}{|c|}{ Dias } & \multirow{2}{*}{ Média } \\
\hline & 1 & 2 & 3 & 4 & 5 & \\
\hline $\begin{array}{c}\mathrm{N}^{\circ} \text { de Amostras } \\
\text { processadas }\end{array}$ & 53 & 54 & 46 & 178 & 132 & 92,6 \\
\hline
\end{tabular}

No entanto, a experiência dos operadores no trato com o material, bem como as condições do maquinário e uma finalidade para o material baseada num projeto de produto intervieram no número de sub-amostras serradas. Visando a sua melhor adaptação aos cortes 
no desdobro de toras resultando em melhoria na eficiência técnica.

\section{VIABILIDADE DE USO, FATORES LIMITANTES E SUGESTÕES DE UTILIZAÇÃO PARA MATÉRIA-PRIMA}

Em termos de viabilidade o uso da parte periférica do estipe de pupunha, considerando dados referentes ao rendimento e a eficiência do experimento, conduzem a visão sistêmica para capacidade da produção de novos produtos e artefatos.

Considerando com uma única unidade as amostras extras e da base, a soma da secção constitui 52,93 \% do rendimento do experimento e eficiência de 16,71 m3/operário/ turno (Tabela 9) constituindo os maiores valores. Como antes relatado a secção do meio obteve o maior rendimento individual de $41,78 \%$, porem a eficiência correspondeu o menor valor com 3,43 m3/operário/turno (Tabela 9). Enquanto a projeção de uso do estipe a $25 \mathrm{~cm}$ do ponto médio para ao rendimento foi de $49 \%$ (Tabela 9).

Tabela 9: Descrição do rendimento e eficiência do experimento. Legenda: (M) Meio, (B) Base e (EXB) Amostras extras da base.

$$
\begin{array}{ccc}
\text { Secçăo No de } & \text { Rendimento } & \text { Eficiência } \\
\mathrm{m}^{3} / \text { operário/turno }
\end{array}
$$

\begin{tabular}{cccc} 
M & & 41,78 & 3,43 \\
BXB & 41 & 23,86 & 16,71 \\
& & 29,07 & \\
\cline { 2 - 4 } & & 94,71 & 20,14 \\
\hline & Total & 31,57 & 10,07 \\
\hline $\begin{array}{l}\text { Média } \\
\text { pesvio }\end{array}$ & 9,22 & 9,39
\end{tabular}

Fonte: Elaborado pelos autores

A secção base e suas amostras extras satisfazem conforme a literatura de outras espécies que apresentam o rendimento médio entre $45 \%$ (POLZL, 2003) a 52,3\% (BORGES et al.,1993) e correspondem segundo Rocha (2002) rendimento de $45 \%$ e $55 \%$ para folhosas.

Com base nos dados apresentados referentes ao rendimento e eficiência do experimento (Tabela 9), e da projeção do uso do estipe com altura média de 5,25 m, demonstram que a parte periférica proporciona um potencial de uso da matéria-prima sendo como viável o aproveitamento e uma vertente aos produtos e derivados da madeira.

Ao analisarmos por secção o estipe, a região próxima as raízes referentes às amostras extras, o material permite a confecção de móveis e outros artefatos que necessitem de maior resistência.

Bacellar (2010) afirma que a área basal é a mais resistente, porém no presente estudo ressalta como fator limitante a abrangência ao longo do estipe da espessura adequada as propostas de projeto de produtos, e possivelmente limite o tamanho dos objetos.

Outro fator relevante referente à parte periférica, a espessura não está condicionada ao diâmetro. No experimento nota-se a ausência da relação do diâmetro e da espessura dos indivíduos, como exemplo são os indivíduos 2 e $15 \mathrm{com}$ DAP's de $13 \mathrm{~cm}$ e $11 \mathrm{~cm}$, e espessura média de $0,5 \mathrm{~cm}$ e $1,4 \mathrm{~cm}$.

Em contraponto a resistência da área basal, a rigidez do material dificulta a laminação da matéria-prima. A estipe de pupunha apresenta uma composição visual entre fibras escuras e claras (Figura 4); essa composição orgânica possibilita um leque de propostas e novas composições aplicáveis tanto projeto de produto como em projetos visuais, como o exemplo do design de superfície.

Figura 04: Amostras extras, vista da parte periférica após a casca (à esquerda) e da parte periférica iniciando transição com a medula (à direita)

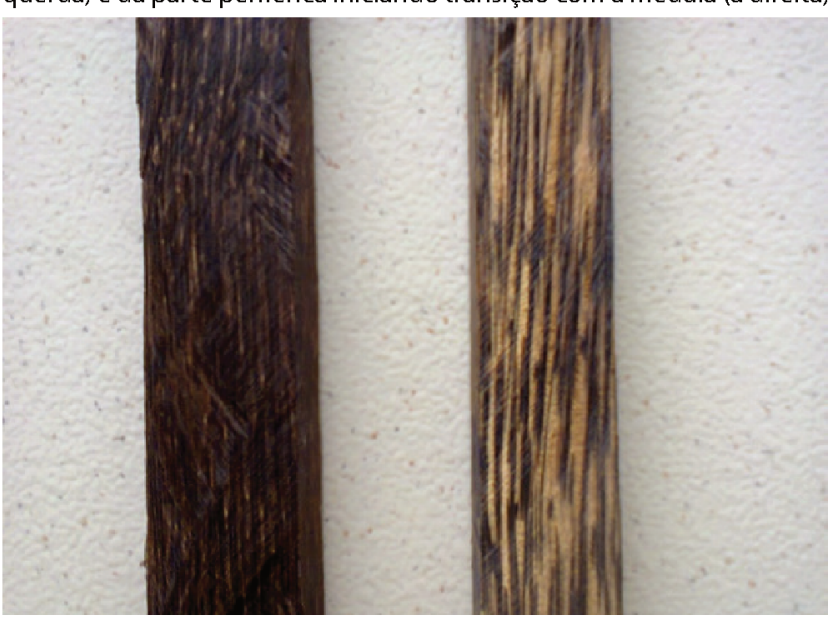

Fonte: Elaborado pelos autores

Embora as amostras da base retirada a 1,5m acima do solo e apresentarem segundo Bacellar (2010) menos fibras orientadas na direção axial, oferecem uma rigidez similar às amostras extras. Assim sendo, encontram-se nas mesmas limitações e aplicações de uso.

Para Bacellar e d'Almeida (2011) a pupunha apresenta valores da tensão de ruptura e do módulo de elasticidade bastante elevados, em comparação com outros materiais lignocelulósicos, e baixos valores para o desvio-padrão. Isso indica uma boa uniformidade do material analisado. Tanto ao ensaio de compressão da pupunha, onde foi possivel enquadrá-la na categoria das madeiras mais resistentes, C60. 
As amostras da secção do meio tem potencial de uso, embora o rigor do material não seja o mesmo das amostras extras e da base. Seu uso seria bem empregado a produtos que comporem espessuras máximas de $0,5 \mathrm{~cm}$, podendo ser uma alternativa a laminação da parte basal.

Técnicas como marchetaria são recursos de aproveitamento da matéria-prima, bem como o refugo descartado no desdobro, possibilitando o desenvolvimento de diversos objetos nas mais variadas linhas (decoração, objetos pessoais, de escritórios, de uso cotidiano e dentre outros).

A exemplo disso, está o trabalho de Silva et al (2005) que solucionou os problemas de desperdício da matéria-prima e criando-se novas peças, a partir desses resíduos que é descartada diariamente durante o processo de fabricação. E ao acrescentar outros materiais aumenta as probabilidades de aceitação do mercado.

O incremento competitivo dos produtos brasileiros deve, portanto, ser conseguido pela diferenciação qualitativa obtida com a agregação de valor e aumento do valor percebido pelos consumidores. Produtos com uma indicação de sua procedência e que remetam à cultura e aos valores de sua região são atualmente melhor diferenciados e valorizados no mercado global, sempre ávido por novidades (TRINDADE, 2005).

Quanto à aplicação da parte periférica do estipe em ambientes o qual o produto lida com intempéries ou água e outros líquidos. Deve-se atentar para as especificações da quanto às características físicas e mecânicas, bem como o manuseio e execução do material. Em ensaio de abrasão, a pupunha apresentou um desgaste muito inferior aos desgastes apresentados por diversas madeiras, o que a torna adequada ao uso como revestimento (BACELLAR e D'ALMEIDA, 2011).

Em ensaios de exposição ao tempo, com raios UV e unidade, houve redução na resistência, demonstrando além de valores altos para modulo de ruptura (MOR) e modulo de elasticidade (MOE) resiste bem à exposição ao tempo; e comparado a fibra de vidro (compósito sintético) obteve uma redução aproximada de $10 \%$ no MOR (BACELLAR, 2010). Envelhecimento em água, álcool ou óleo de peroba causou redução do modulo de armazenamento, sem afetar a estrutura do material (D'ALMEIDA e D'ALMEIDA, 2009). Embora que, tratando-se da durabilidade a ataques de agentes xilógrafos, em ambiente florestal a vida útil foi limitada há 18 meses (ABREU e JESUS, 2004).

Quanto ao cisalhamento na lamina de cola, a combinação pupunha e cascophen são muito resistentes para amostras de $3 \mathrm{~mm}$ e $10 \mathrm{~mm}$, chegando a se comparar a resistência ao cisalhamento na madeira (BACELLAR e
D'ALMEIDA, 2011). Dados como este, superam o principal problema da parte periférica da pupunha que é o melhor aproveitamento do material.

Pesquisadores do Instituto Nacional de Pesquisa na Amazônia - INPA e da Universidade Federal do Amazonas - UFAM, também nortearam o uso do material lenhoso da pupunheira em produtos. O pesquisador Jadir Rocha aproveita a madeira da pupunheira para a fabricação de móveis (Figura 5), artefatos e biojóias, bem como o painel modular com pastinhas decorativas (Figura 6) desenvolvidas pela Engenheira Florestal Alessandra Fonseca.

Contudo, o maior fator limitante do material é encontrar indivíduos com material lenhosos suficientes e aptos ao projeto, devido à espessura e sua relação ao comprimento, como também o abate e o beneficiamento para obtenção da parte periférica.

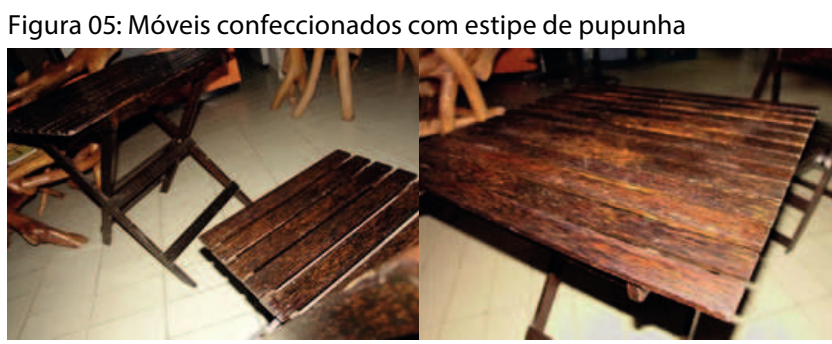

Fonte: Portal Amazônia.

Figura 06: Painel decorativo com pastilhas de pupunha

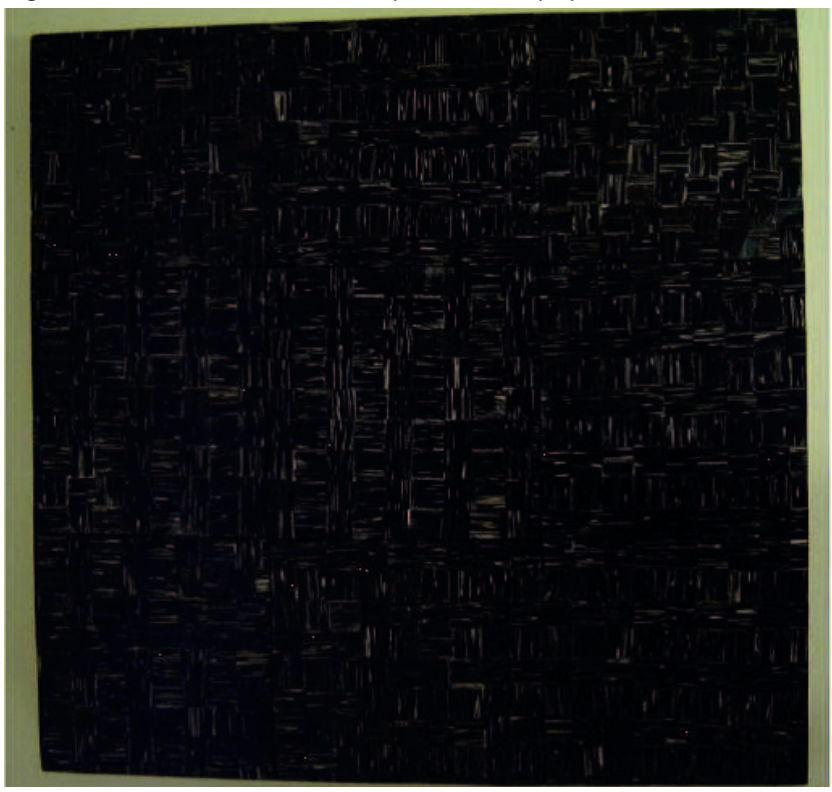

Fonte: Portal Amazônia

\section{CONCLUSÕES}

A parte periférica do estipe de pupunha evidencia um potencial de uso para diversos produtos pela rigidez, tenacidade e beleza. Devido à composição visual 
da estrutura apresenta um diferencial para aplicação. Se levadas em contas as características físicas e mecânicas na aplicação no determinando produto a ser produzido a chances de sucesso entorno da qualidade e resistência.

O rendimento das amostras do estipe de pupunha obtido por meio do desdobro apresentaram uma média $31,57 \%$, satisfatório, comparados aos resultados das coníferas (45\% a 55\%). Embora o volume residual do experimento seja considerável alto, devido à presença mesmo que pequena da parte medular. Contanto, o rendimento contemplou valores a espécies de alto rendimento, bem como a projeção de uso do estipe até o ponto mediando do indivíduo, de 49\%.

Ao contemplarmos a viabilidade do uso da parte periférica do estipe os dados referentes ao rendimento e eficiência do experimento (Tabela 9) conduzem ao aproveitamento para desenvolvimento de novos produtos e artefatos. Permitindo uma visão da capacidade de produção ao atender uma possível demanda, salientando que os planejamentos da matéria-prima, bem como a projetação do produto determinarão o melhor rendimento e eficiência de produção.

\section{REFERÊNCIAS}

ABREU, R.; JESUS, M. Durabilidade natural do estipe de pupunha (Bactris gasipaes Kunth, Arecaceae). II: Insetos. Acta Amazonica, 34(3): 459 - 465. 2004.

ARAUJO, M. Produtos Ecológicos para uma Sociedade Sustentável. IDHEA - Instituto para o Desenvolvimento da Habitação Ecológica. Artigo publicado em 2010. Disponível em: <www.IDHEA.com.br> acessado: 25/04/2015.

BACELLAR, R. Caracterização Microestrutural e Mecânica de Resíduos da Agroindústria. Dissertação. PUC-RIO. Rio de Janeiro. 2010

BACELLAR, R.; D'ALMEIDA, J. Caracterização mecânica de resíduos da agroindústria de palmito pupunha e de coco. Desenhando o Futuro. $1^{\circ}$ Congresso Nacional de Design. Bento Gonçalves. Rio Grande do Sul. 2011

BACELLAR, R.; D’ALMEIDA, J. Caracterização Microestrutural e Mecânica da Pupunha. Rio de Janeiro: PUC-RIO, 2008. 12 p.

BATISTA, D.; CARVALHO, A. Avaliação do desempenho operacional de uma serraria através de estudo de tempo, rendimento e eficiência. Scientia Forestalis, 2007. 75:31-38.

BIASI, C.; ROCHA, M. Rendimento em Madeira Serrada e Quantificação de Resíduos para Três espécies Tropicais. Revista Floresta, Curitiba, v. 37, n. 1, 2007.

BORGES, A.; GINIGLIO, G.; BRITO, J. Considerações energéticas e econômicas sobre resíduos de madeira processada em serraria. In: CONGRESSO FLORESTAL PANAMERICANO, 1., 1993, Curitiba; CONGRESSO FLORESTAL BRASILEIRO, 7. 1993, Curitiba. Anais... São Paulo : Sociedade Brasileira de Silvicultura, 1993. v. 3. p. 603-606.

D'ALMEIDA, A.; D'ALMEIDA, J. Efeito da Exposição da Madeira de Pupunha a Água e a Produtos Químicos: Análise Termo-mecânica. Anais do 10 o Congresso Brasileiro de Polímeros. Foz do Iguaçu, PR .Outubro/2009

FIBRA DESIGN SUSTENTÁVEL. Palmito Pupunha torna-se matéria prima para Design. 2011. Disponível em: <http://www.portaldetendencias.com/marco_pupunha. html >. Acessado em: 08/08/15.

FERMINO, M. et. al. Aproveitamento dos resíduos da produção de conserva de palmito como substrato para plantas. Horticultura Brasileira, v. 28, p. 282-286, 2010.

FONSECA, A. Confecção de Pastilhas Decorativas para Ambientes Internos a partir do Estipe de Pupunha (Bactris gasipaes H.B.K): Arecaceae. 94f. Monografia (Projeto de Graduação em Engenharia Florestal) Universidade Federal do Amazonas, Manaus, 2010.

GIORDANO, B. Resíduos do processamento da Palmeira-Real (Archontophoenix alexandrae) na Fazenda Princesa do Sertão: implantação da indústria para a fabricação de biscoitos fibrosos. 2007. 68 p. TCC. Centro de Ciências Agrárias, Universidade Federal de Santa Catarina, Florianópolis, 2007.

GOUVINHAS, R.; ROMEIRO FILHO, E. Projeto para o Meio Ambiente. In: Projeto do Produto. Rio de Janeiro: Elsivier, 2010.

HILLIG, E; SCHNEIDER, V.; WEBER, C; TECCHIO, R. Resíduos de madeira da indústria madeireira - caracterização e aproveitamento. In: Anais do XXVI 
ENCONTRO NACIONAL DE ENGENHARIA DE PRODUÇÃO, 26., 2006, Fortaleza. Anais do... Fortaleza, 2006. p. 7.

LEEUWEN, J. O melhoramento participativo da pupunheira (Bactris gasipaes) para a produção de fruto, uma proposta preliminar. In: ProBio: Pupunha: raças primitivas e parentes silvestres. Manaus: INPA, 12p, 2006.

MADY, F. Aspectos da anatomia do estipe de Euterpe Oleraceae Mart. (Arecaceae): palmeira utilizada em sistemas agroflorestais. Dissertação de Mestrado. Universidade Federal do Amazonas. Manaus - AM. 31p. 2003.

MANHIÇA, A. Rendimento e eficiência no desdobro de Pinus sp. utilizando modelos de corte numa serraria de pequeno porte. 85 f. Dissertação (Mestrado em Engenharia Florestal) Universidade Federal do Paraná, Curitiba, 2010.

POLZL, W.; SANTOS, A.; TIMOFEICZYK, R.; POLZL P. Cadeia produtiva do processamento mecânico da madeira - Segmento da madeira serrada no Estado do Paraná. Revista Floresta. 2003. No; 33(2), pag 127-134.

PUPO, H. Painéis Alternativos Produzidos a Partir de Resíduos Termoplásticos e da Pupunheira (Bactris Gasipaes Kunth). 2012. Dissertação (Mestrado em Agronomia - Energia na Agricultura) - FCA, Universidade Estadual Paulista "Júlio de Mesquita Filho", campus de Botucatu: Fev/2012.

ROCHA, M. Técnicas e Planejamentos de Serrarias. Curitiba: FUPEF, 2002.

ROSA, E.; PAMPLONA, E.; ALMEIDA,D. Parâmetros de desempenho e os Elementos de Competitividade. In: ENCONTRO NACIONAL DE ENGENHARIA DE PRODUÇÃO, 160., 1996. Piracicaba. Anais do Encontro Nacional de Engenharia de Produção Piracicaba: ENEGEP, 1996.

SEBE, L.; PAULA, I.; VIANA, A. Análise do Processo de Beneficiamento da Palmeira Real da Austrália (palmito em conserva) para determinação das variáveis que influenciam as operações de valorização de seus resíduos. In: $8^{\circ}$ CONGRESSO BRASILEIRO DE GESTÃO DE DESENVOLVIMENTO DE PRODUTO, 8., Porto Alegre. Anais do Congresso Brasileiro de Gestão de Desenvolvimento de Produto. Porto Alegre: CBGDP, 2011.
SILVA, F. et al. Aproveitamento de Resíduos da Agroindústria do Palmito no Vale do Ribeira. Revista Brasileira de Agroecologia, v. 4, n. 2, p. 2595 - 2598. 2009.

SILVA, H.; MOUC, I.; BASTOS, M. Reaproveitamento de Resíduos de Madeira Oriundos da Marcenaria da Fucapi. T\&C Amazônia. Ano III. No 7. Julho. 2005

SILVA, K. Utilização do Estipe da Pupunha (Bactris gasipaes, Kunth) para Móveis e Utensílios. 2010. Monografia - FCA, Universidade Federal do Amazonas, Manaus: 2010. 